\title{
ALGUNS PROCEDIMENTOS DE NIKOLAI LESKOV E A DIFICULDADE DA SUA TRADUÇÃO
}

\author{
Noé Silva*
}

RESUMO: O autor discute alguns traços do estilo do escritor, com ênfase no trabalho de Leskov com as palavras (uso fora do contexto normal, corrupção, invenção). Em paralelo, comenta duas traduções, uma espanhola e uma estadunidense, do conto "O canhoto", bem como as possibilidades de transmissão do sentido do original em Português.

UNITERMOS: Leskov; tradução; poética; semântica; sintaxe.

ABSTRACT: The author discusses a number of Leskov's stylistic characteristics, focusing on the way he uses Russian words (usage out of normal context, corruption, invention). He also comments on the Spanish and American translations of the short story "Levsha/Lefthand" and examines the possibilities of delivering the original meaning in Portuguese.

KEYWORDS: Leskov; translation; poetics; semantics; syntax.

Dos escritores russos clássicos do século XIX, um dos que mais dificultam o trabalho dos tradutores é Nikolai Leskov. Figura isolada no meio literário, por motivos políticos e por características

* Prof. Dr. do Departamento de Letras Orientais da Faculdade de Filosofia, Letras e Ciências Humanas da Universidade de São Paulo (USP). 
da sua escrita, como um herege entre pios e um malicioso entre puros, ele dizia que os seus textos eram reconheciveis até sem a sua assinatura e que o que se lia, na maioria dos seus livros, era a linguagem sorrateiramente apanhada, durante as suas muitas viagens pela parte europeia do país, da boca dos mujiques, dos pseudointelectuais, das pessoas bem falantes, dos mendigos videntes e dos santarrões. Pelas palavras de um crítico de então, Leskov erigira um "museu de todos os falares" da Rússia, com "todos os elementos do oceano da linguagem russa" (Olieg Miénchikov), como a dos cronistas históricos, a de salão, a dos funcionários públicos, a dos contos maravilhosos, a dos padres de aldeia, a dos dogmáticos e escolásticos, a dos andarilhos e dos artesãos. Ao resultado desse trabalho de Leskov, Viktor Chklóvski, no livro Teoria da prosa, chamou "um enorme, verdadeiro, poderoso e novo russo, a rocambolesca linguagem dos pequeno-burgueses e dos parasitas".

O tradutor vê-se diante de palavras inventadas e de uma linguagem torcida, num grau e numa quantidade, às vezes, exagerados. Tais excessos contribuíram para o malogro de alguns escritos de Leskov, os quais, ao contrário de contos como "O artista dos topetes" (Tupiéinyi khudójnik), "Kotin e Platonida" e "A voz da Natureza" (Gólos priródy), de pouco torcimento da linguagem e de quase nenhum desvio do léxico estabelecido, não permitem ao leitor ver o grande contador de histórias que Leskov era. Por outro lado, novelas como "O anjo selado" (Zapetchatliónnyi ánguel) e "O peregrino encantado" (Otcharóvannyi stránnik), de fatura marcadamente leskoviana, constituem verdadeiras obrasprimas. Paradoxo? Não, apenas a demonstração de quão escorregadia era a senda, trilhada por Leskov, em cujas obras, às vezes, a riqueza tem como vizinha a gabolice pelintra, o desperdício espreita de trás da generosidade e a originalidade parece afetação. Ademais, muitas palavras inventadas por ele não têm graça nenhuma e não se caracterizam pela funcionalidade, ou seja, não importam em ganho de expressividade; às vezes, até ocorre que ninguém ou quase ninguém as entende.

Assim, o tradutor deve decidir: tentar reproduzir os procedimentos de Leskov na língua de chegada ou pasteurizar o texto? A única atitude de um tradutor honesto só pode ser abalançar-se à primeira alternativa. Para tal ele deve: entender o que Leskov faz,

TRADTERM, 15, 2009, p. 41-58 
como o faz e para que o faz. Tentaremos clarificar tais pontos com exemplos de "O canhoto", considerado o "padrão da linguagem" de Leskov. Tangencialmente, comentaremos algumas passagens, tais como aparecem numa tradução espanhola ${ }^{1}$ e noutra estadunense ${ }^{2}$.

A história começa com a visita do czar e do general Plátov a um museu inglês de assombrosidades. Leskov faz da linguagem viva da personagem o caminho mais seguro para a penetração na psicologia do caráter. Plátov caracteriza-se pela ânsia de voltar para casa e pelo desdém a todas as coisas não russas, sejam elas palavras ou objetos: o narrador como que se põe ao lado da personagem e reproduz-lhe o ânimo, com palavras estropiadas, inventadas ou usadas fora de contexto. Assim, conversas "em Francês" tornamse "conversas francesas" (frantsúzkiie razgovóry), perda de tempo e saliva, "pura futilidade, em que não valia a pena gastar a imaginação"; fale-se Russo, pois! A carruagem inglesa é de dois "sentares" (dvukhsiéstnaia), porque inferior à russa, que esta, sim, é de dois "lugares" (dvukhmiéstnaia, a palavra certa); mikroskop (mckroscópio) transforma-se em melkoskop (miudoscópio), com a substituição do prefixo grego mikros, denotador de pequenez, pelo equivalente russo miéllko; a mesma tentativa de despaganização de termo estrangeiro faz-se em buremietr (rus. Búria - tempestade; temporómetro) em substituição ao correto barómetr (gr. Baros-peso; barómetro). A sanha contra as palavras de origem estrangeira faz o narrador fundir biusty (bustos) e liustry (lustres), de origem francesa, em bustres (afinal, o que é estrangeiro é tudo uma coisa só, sem nenhum valor que as individualize); tal procedimento também provém da impaciência de Plátov diante daquele número infindável de salas, bustos, lustres e demais estrangeirices tão do agrado do czar; ele quer é ir-se o mais depressa possivel da Inglaterra. As palavras ditas pelos ingleses, para ele, um xenófobo, são apenas sons desagradáveis e, assim, ele mistura os nomes de coisas distintas (como em bustres), e a famosa estátua Torso del Belvedere, do escultor ateniense Apolónio, torna-se Abolón Polvediórskii (algo como Abolão

1 LESKOV, Nikolai (2007) La pulga de acero. Madrid: Editorial Impedimenta, trad. de Sara Gutiérrez.

2 LESKOV, Nikolai (2003) The enchanted wanderer. New York: Random House, trad. de David Magarschak.

TRADTERM, 15, 2009, p. 41-58 
de Meiobaldérskiu) ou, se quisermos reproduzir mais ostensivamente o efeito depreciativo do original, Abolão de Meiatijelérskii. Em suma, a xenofobia e a impaciência da personagem contagiam o narrador. Leskov quis tanto assinalar tais traços da personagem que, ao entusiasmo do monarca pelas coisas dos ingleses, o militar responde:

- Cá a única coisa que me admira é que os meus bravos do Don sempre lutaram sem nada disso e ainda assim expulsaram as doze linguas.

Vede bem: usa-se a expressão "as doze línguas", com que os Russos designavam o exército de Napoleão, constituído não só de Franceses; portanto, a deturpação dos nomes de coisas e pessoas constitui o meio de expressão da xenofobia da personagem. A tradutora espanhola não deixou isso passar em branco (pequescopio, Abolón de Malvedere, tormentómetros, cerámides etc.), embora tenha errado no numeral:

- A mi de aquí me asombra solo uma cosa - respondió Plátov -: que mis chicos del Don lucharon sin nada de esto $y$ expulsaran a las veinte lenguas. (p. 34)

Já o tradutor estadunidense limitou-se a um "Apollo Belvebeery”, que, pela presença de beer (cerveja), fica com ar simpático, quando, na verdade, a intenção, no original, é inequivocamente depreciativa. Apagou, outrossim, todas as marcas de algo importante para o Autor:

- The only thing that impresses me, your Majesty, is that my gallant Cossacks won so many battles and routed thousands of your enemies without any of the things here. (p. 214)

Ora, entre os "milhares de inimigos" do czar, havia também os milhares de russos inimigos do regime autocrático ou de camponeses sublevados, mas eles, seguramente, não estavam entre as "doze línguas", porque a sua era a do próprio Plátov; portanto o leitor pode ser induzido em erro.

TRADTERM, 15, 2009, p. 41-58 
Leskov realiza a manipulação do léxico nas proximidades sônica e semântica da palavra, tirando do contexto a força de atração para esta ou aquela combinação de letras. Para ele, as palavras distribuem-se no nosso espaço mental como as estrelas no céu; cada uma reúne, em torno de si, todas aquelas com as quais condivide silabas (talvez, mais exatamente: à sua volta, pairam todas as letras do alfabeto) e, nessa sua área de, digamos, influência, podem encontrar-se até palavras estrangeiras. O procedimento não só tem grande efeito cômico, senão também produz palavras com maior carga semântica.

Por exemplo, no idioma russo entrou a palavra alemã Stiefeletten (bota masculina com atacadores), sob a forma штиб.леты (chtibliéty). Substitui-se o IIIT (cht) inicial por uma consoante de som muito próximo, แ' (lê-se "chtchá", transliterado como chtch); tal consoante, ao lado de и (lê-se "i"), forma a palavra significadora de "sopa de repolho"; com isso, o pedaço -леты (-liéty) aviva-se e evoca кот.леты (kotliéty, "almôndegas"), de modo que, por fim, o leitor vê-se diante de um tipo de calçado de excelente qualidade e, também, despertador do apetite.

E para que tanto trabalho da parte de Leskov? Na época da ação da história do artesão canhoto de Tula, na Rússia havia a escravidão; os servos andavam maltrapilhos e passavam fome; os trabalhadores ingleses, por sua vez, no entender de Leskov, eram livres, tinham vestes decentes e, por calçarem tão boas botas e sapatos, eram também bem alimentados. Aqui, era preciso mexer no nome do calçado para fazê-lo lembrar algum tipo de comida:

Cada trabajador está permanentemente saciado, vestido no con harapos, sino con un chaleco apropiado para cada ocasión, calzado con gruesos botatos con refuerzos de hierro. (p. 103)

Em Português, "bota" permite-nos botatas (paroxitona mas com ó, aberto). Decidimos acrescentar, por nossa conta, outro tipo de calçado, "sapatos", pois fornecem mais um prato aos trabalhadores ingleses:

Cada trabalhador deles está sempre saciado de comida e vestido não com farrapos, senão com um colete apropriado

TRADTERM, 15, 2009, p. 41-58 
para todos os dias, e calçado com grossos e casquilhos botatas e sopatos com reforços de ferro.

Em Inglês, supomos, tal manipulação das palavras parece não ter sido possivel:

Every one of their workershad enough to eat, and he was not dressed in rags, but wore a good jacket and thich leather, iron shod-boots. (p. 244)

Também na parte do relato da estada do canhoto em Inglaterra e na linha da crítica à ordem social da Rússia, aparece boilo, outra invenção de Leskov, em grande exemplo da sua linguagem torcida, votada a não dizer as coisas diretamente e, ao mesmo tempo, fazê-lo de modo expressivo. Ele tomou vóilo ("feltro") e substituiu o som inicial de "v" por "b"; com isso, transformou a sílaba tônica da palavra em boi ("combate", "luta"; por extensão, no dado contexto, "pancada", "bordoada"). Qual o resultado disso? A parte mais altissonante da palavra converteu-se precisamente no oposto da ideia expressa pela palavra original inteira: boilo $\rightarrow$ bordão, bordoada $\rightarrow$ violência / / afago, carícia $\leftarrow$ voilo (feltro). O português feltro não permitiria a conservação do efeito do original e, por isso, teve de buscar-se outro estofo ou pano relacionado com lã ou pelos e, dele, produzir um termo equivalente. Nos termos da nossa tradução, a correlação ficou: pelúcia $\rightarrow$ afago, carícia // violência $\leftarrow$ paulada, pau $\leftarrow$ paulúcia.

He did not do his work because somebody stood over him with a whip, but because he had been taught his trade. (p. 244)

Trabaja no com golpes, sino com enseñanza, y comprende lo que hace. (p. 103)

[trabalha não com paulúcia, senão com ensinamento, e compreende o que faz.]

Como pode ver-se, para Leskov a palavra não é um todo indivisivel; é, sim, composta de partes, que podem agir por conta própria, no sentido de combinarem-se com letras de fora da pala-

TRADTERM, 15, 2009, p. 41-58 
vra; enfim, em cada palavra há palavras inteiras e pedaços de outras. Portanto, cada palavra, cada significante de uma ideia tem, dentro de si, pedaços dos significantes de outras ideias. Basta uma letra de fora dela, sozinha ou combinada com outras, achegar-se às suas sílabas, que sejam o tronco do significante de uma ideia ali existente em potência, para que tal ideia se avive, ganhando os faltantes membros e, com isso, expressão plena.

Ora, após o retorno do czar e de Plátov à Rússia, o primeiro, achando-se muito doente, decide ir a uma cidade do Sul para confessar-se a um padre e dispensa os préstimos do segundo, porque este não tem "a necessária contenção para conversas espirituais". Plátov, ofendidíssimo nos seus brios, vai para casa e deita-se no seu canapé (duquesa). Não é dito mais nada ao leitor, mas a este sugere-se toda uma tragédia pessoal. Plátov está irado; vira-se e revira-se de um lado para o outro e tenta aliviar o amargor do despeito com quilos de tabaco, mas tudo o que consegue é ficar ainda mais ofendido, virar-se e revirar-se ainda mais naquele móvel, como se picado por percevejos. Com as meras quatro sílabas de uma palavrinha inventada e, escusa dizer, muito engraçada ukuchetka - Leskov dá-nos toda a vivência, intensa e sofrida, da desfeita sofrida pela personagem. Plátov podia haver-se deitado numa cama, num sofá, sobre um colchão, um tapete ou mesa ou sabe-se lá mais o quê, e até sobre o chão, mas, não, fê-lo precisamente numa kuchetka (sem aquele $u$ inicial, que lhe dá Leskov), e esta, literalmente, morde-o, pica-o.

Leskov confere vida ao canapé (ou duquesa), partindo do fato de que, na língua russa (como na portuguesa, aliás), os estados de zanga e irritação podem ser expressos pelo verbo ukussit' (morder, picar). Diz-se: Kakaia evó mukha ukussila? (Que mosca o picou? Para nós: Que bicho o mordeu?), em relação a alguém que se mostre muito zangado, irritado. A personagem está picada pelo despeito, mordida nos seus brios: o kuch da palavra kuchetka precisava apenas de mais uma letrinha de fora (no caso, "u") para materializar o estado de espírito da personagem, ou seja, para transformar uma inerte kuchetka (canapé, duquesa) numa incómoda ukuchetka (bocanhapé, mordequesa):

Platov was thus left behind to nurse his grievance, and he lay down on his couch and sulked and all the while he lay

TradTerm, 15, 2009, p. 41-58 
on his couch he went on smoking Zhukov tobacco without stopping. (p. 220)

Plátov se quedó ofendido y se fue a casa a tumbarse en el lecho del despecho, donde permaneció tumbado fumando tabaco Zhukov sin descanso. (p. 46)

Plátov ficou ofendido e, em casa, deitou-se no seu bocanhapé de despeito, e nele permaneceu deitado, a fumar tabaco Júkov sem parar.

Achamos indispensável ao menos a tentativa de preservação do efeito do original na citada passagem (na história, há outra situação semelhante) e, para isso, há duas razões. Em primeiro lugar, Leskov escrevia, preferencialmente, no skaz, gênero épico, cujas principais características são: a) está próximo da arte popular oral (da bylina, lenda, conto maravilhoso, anedota); b) o principal, nele, não são tanto os acontecimentos e os caracteres, quanto a personalidade do narrador e a sua linguagem; e c) o narrador, via de regra, é uma pessoa do povo, por isso a sua linguagem é cheia de dialetismos, ditos populares e eufemismos; em presença de um tal narrador, os acontecimentos retratados são percebidos por meio dos olhos de uma pessoa do povo.

O skaz, juntamente com a estilização, é o principal método da estilística de Leskov. Na maioria dos seus contos e novelas, o relato faz-se por um narrador, cuja peculiar maneira de falar ele tenta transmitir. Tal narrador é extremamente permeável ao modo como a personagem, geralmente um camponês, trabalhador braçal ou citadino analfabeto, reage a fatos alheios à sua experiência de vida e a palavras a ele incompreensiveis.

Pois bem, é mais do que natural que uma tal pessoa, ao falar de coisas a ela estranhas ou nada familiares, deturpe os seus nomes, e ela o faz de acordo com a ideia que tais coisas lhe suscitam, e em consonância com as que conhece; assim, mikroskop ("microscópio") torna-se melkoskop ("miudoscópio", para enxergar o que é miudinho), piramida ("pirâmide") deu keramida ("cerâmide", de "cerâmica", pois "pirâmide" devia ser algo grande de louça) e vestovýe ("ordenanças") foram rebatizados como svistovýe ("assobianças", pois acodem ao assobio, "svist", do superior) etc.

TRADTERM, 15, 2009, p. 41-58 
Em segundo lugar, Leskov, como tão bem disse o seu maior admirador, Maksim Górki

escrevia não plasticamente, e, sim, contava, e nisso era incomparável... Tolstói e Turguiénev gostavam de criar, em torno da personagem, este ou aquele fundo, que a animasse de modo mais bonito, e recorriam largamente à paisagem, bem como à descrição do curso dos seus pensamentos e do jogo dos seus sentimentos. Leskov quase sempre evitava isso, atingindo os mesmos resultados por meio da fina urdidura da renda nervosa da fala coloquial. (Górki, 1952:49)

Os acontecimentos, os fatos e as coisas não impõem ao narrador leskoviano as suas características e traços objetivos; a personalidade dele converte-as na moeda corrente do seu conhecimento da vida; ele traduz os conceitos, as ideias, tudo o que lhe é abstrato e estranho nos termos da sua experiência prática e nisso revela algo de si. Pois bem, a palavra ukuchetka constitui o registro estenográfico do estado de alma da personagem em determinado momento; à semelhança do orificio que, em certos aparelhos mecânicos, dá passagem aos vapores, ela e outras são respiradouros, por onde sai um pouco da alma da personagem.

São inúmeros os exemplos da habilidade de Leskov no manuseio das palavras, cuja escolha se dá em paralelo com o desenvolvimento do enredo; o autor segue as indicações do contexto, o qual tem as suas exigências, e delimita, de alguma forma, o vocabulário para este ou aquele momento da ação. As palavras não são apenas letras alinhadas de modo coerente - elas são caixas com ideias que, como molas comprimidas, estão à espera somente do toque certo, sugerido pelo contexto dentre as possibilidades oferecidas pelo idioma.

Se a história da pulga de aço e do canhoto vesgo de Tula constitui o produto mais acabado da perícia de Leskov no campo da linguagem, queremos distinguir nela aquele que consideramos o exemplo máximo da sua capacidade de manipular as palavras $(\mathrm{O}$ verbo "manipular" remete-nos a "manuseio", e o que se vê é uma espécie de prestidigitação: veicula-se o significado de uma palavra e, ao mesmo tempo, omite-se o seu significante; a palavra aparece

TRADTERM, 15, 2009, p. 41-58 
fortalecida, como que havendo incorporado os significados das outras, sob as quais é escondida). Por dois motivos: o substantivo tomado como ponto de partida para o jogo e o fato de que se opera não com ele, mas com um seu simulacro.

Trata-se do nome do prato comido, no desjejum, pelo marujo inglês na embaixada do seu país, ao recuperar a consciência com a ajuda de um médico e de um farmacêutico, depois da bebedeira de vários dias. Está escrito literalmente: kúritsa s rýss iu, "galinha com lince" (É corrente a opinião de que a carne do lince, pelo fato de esse ágil felino comer só carne fresca, possui especiais propriedades tonificantes). Entende-se, naturalmente, outra coisa, e com um riso. A expressão $s$ rýss iu é muito parecida a $s$ ríssom, "com arroz"; lidas de corrido, elas se confundem. "Lince", em Russo, é rys (y é a transliteração de um " $l$ " duro, pronunciado mais no fundo da garganta do que o nosso " $i$ '). Pois é quase exatamente isso o que se ouve da boca de um inglês que queira dizer a palavra russa pHC (ris, "arroz"), pela sua velarização da letra $r$, e Leskov entendia muito bem do assunto, já que tinha um tio dessa nacionalidade (marido de uma irmã da sua mãe) e trabalhara largos anos com ele. Leskov foi além; havendo dissimulado o arroz sob a aparência de lince, torna-o, digamos assim, mais nutritivo de sentido, com o atirar-lhe para cima o significado de mais uma palavra, o do advérbio rýss 'iu ("como um lince", que quer dizer "a trote"). Assim, tem-se uma galinha não apenas com lince, mas também com trote ou a trote. Ou seja, Leskov serve à personagem um arroz mais refocilante e nutritivo em calorias do que o comum: um arroz, que fará o marinheiro sair com a energia e o trote de um lince, em procura do amigo russo; senão, não o haveria encontrado de modo tão rápido numa cidade grande como o era já São Petersburgo à época.

Vejamos o que escreveu a tradutora espanhola, no seu prefácio, acerca dessa invenção de Leskov:

Baste indicar, por ejemplo, que la letra que se cuela en el arroz que un personaje desayuna, aportándole una energia excepcional, parece proceder de un vocablo que significa al trote. Yo he condimentado el arroz con arrear esperando que el arreoz guste igual. (p. 27)

TRADTERM, 15, 2009, p. 41-58 
A sua suposição esteve perto da verdade, e é satisfatória a sua solução, com o recurso que, por coincidência, nós também, inicialmente, fizéramos, à interjeição arre, de origem árabe, usada pelos tropeiros para pôr em marcha os seus animais:

Al día siguiente, el semimaestre inglês se levantó, tragó outra pastilla de gutapercha, tomó un desayuno ligero a base de gallina con arreoz, bebió erfix y... (p.115)

Feio fez o tradutor estadunidense, que deu sumiço ao arroz servido à personagem por Leskov:

The English sailor got up the next morning at the very time that the Tula gunsmith was being brought to the infirmary, swallowed the second gutta-percha pill, had a quick breakfast of roast chicken, washed it down with soda water, and... (p. 250)

A voz da personagem contaminara a voz do narrador e, com isso, um significante (ríss iu) passou a ser um cacho de significados, com o adendo de não vir expresso (Leskov disse arroz, mas não escreveu arroz e sim uma palavra semelhante a uma cebola, isto é, com várias camadas de sentido). Na impossibilidade de fazer a mesma coisa, tivemos de desdobrar o significado da palavra russa. Servimo-nos da interjeição "eia!", que serve para excitar, animar, e partimos do fato da existência, no Brasil, de um "feijão tropeiro":

No outro dia, a essa mesma hora, o contramestre inglês levantou-se, mandou outra pílula de gutapercha para o bucho, comeu um desjejum leve de galinha com êiarroz troteiro a la lince, tomou erfixo e...

Não temos a pretensão de inventariar todos os artificios de linguagem usados por Leskov na história da pulga de aço, mas eles encaixam-se, uns menos, outros mais, no princípio da manipulação da palavra nos seus arredores sônicos. Agora, é hora de falar da sua capacidade, igualmente admirável, de, sem inventar nada, produzir passagens muito engraçadas e expressivas, com o simples usar de uma palavra corriqueira num contexto que ou the

TRADTERM, 15, 2009, p. 41-58 
devolve o seu significado original com um sabor maroto ou o modifica radicalmente. E, paradoxalmente, essas são as situações de mais dificil reprodução na língua de chegada.

Um belo exemplo da habilidade leskoviana de combinar duas palavras corriqueiras, inocentes, para dar-lhes um significado inesperado encontra-se na conversa do canhoto com os ingleses a respeito de não poder casar-se com uma moça da terra. Aqueles lhe perguntam, então, como procediam os homens solteiros, na Rússia, para manifestarem as suas intenções matrimoniais a alguém, e ele responde-lhes que os seus compatrícios se serviam de uma intermediária. Leskov não seria Leskov, se a personagem desse a essa intermediadora o nome correto, suakha ("casamenteira"). Nós consultamos traduções em vários idiomas e, em nenhuma delas, encontramos ajuda. Os tradutores não atacaram o problema:

In our country, he said, if a man has honorable intentions about a young lady, he sends an old woman who is an expert in such affairs. (p. 242)

A espanhola:

En nuestro pais - dijo -, cuando un hombre quiere una relación seria con una chica, le envia a una casamentera. (p. 99)

Ellos lo entedieron, pero respondieron que em Inglaterra no tenian casamenteras ni existia esa costumbre. (p. 99).

Leskov usa a expressão razgovórnaia jénchtchina (literalmente, "mulher conversal, coloquial"), completamente destituída de parecença com a palavra certa, e subverte o campo de significados do adjetivo; no entanto, a mensagem é entendida. Ora, direis, mas que é que permite a uma "mulher conversal, coloquial" passar por "casamenteira"?

Assim como uma pessoa revela muito de si, quando posta em situação inusitada, o dado adjetivo, no papel de modificador de um substantivo de fora do seu campo de aplicação habitual, põe em relevo um seu lado esquecido pelos falantes, um matiz de sig-

TradTerm, 15, 2009, p. 41-58 
nificado, que o uso corrente da palavra parece haver já desgastado; o seu significado primevo ressurge com uma graça insuspeitada; o ouvido enche-se dos ecos do seu radical e de termos afins. Ora, a "casamenteira" (razgovórnaia jénchtchina) dirige as "conversações" (peregovóry) entre um homem e uma mulher. É pessoa de boa lábia, dotada do talento "de conversar" (razgovárivat), discreta na vida privada, mas, em serviço, "loquaz" (govorlivaia), talvez até "tagarela" (govorún ia), senão não consegue "persuadir" (ugovorit) uma parte das excelências da outra; para qualquer alusão a um defeito do(a) pretendente (obesidade, nariz grande, pé chato, estrabismo etc.), ela tem, na ponta da língua, uma série de "ressalvas" (ogovórki); enfim, para essa senhora, que tem de "falar" (govorit) muito, as "conversas" (razgovóry) são como a farinha de trigo para o padeiro, e é com elas que faz os seus "conluios" (zágovory). A ideia da sua "loquacidade" (govorlivost) pragmática e objetiva está, como se pode ver, inalienavelmente ligada ao radical -góvor- (fala, modo de falar) do adjetivo, e é por isso que o adjetivo razgovórnyi (de conversa, "conversal"), no contexto do episódio, evoca tão bem a figura de tão conversante membro da sociedade civil.

Conversar é o que a casamenteira mais faz, e a ação frequentativa do verbo vem sugerida pelo sufixo $-n c ̧ a$, forma contrata de -ância, de que Caldas Aulete (1970:223) diz: "Designa continuação, duração, ação contínua, estado permanente, qualidade duradoura: abundância, arrogância, instância, distância, vigilância etc". Se esperança é a ação contínua, o estado permanente e a qualidade duradoura de quem espera por algo, então, o substantivo caracterizador da ação de quem "conversa" o tempo todo e muito (para ganhar a vida, não o esqueçamos), é "conversança" (Cf.: comer $\rightarrow$ comilança). Como esse contínuo conversar deve levar à união do(a) cliente com a pessoa desejada, ou, por outras palavras, que o(a) cliente coloque a aliança de casamento no dedo anular dela, devemos combinar a sucessão de conversas com o limite, a que tende: "conversança" + aliança = "conversaliança". Assim, primeiramente, casamenteira é a "mulher conversaliança", isto é, cujas conversas terminam em anel de casamento.

Para tornar a expressão ainda mais engraçada, acresce o fato de que o adjetivo possui, também, o significado de "próprio do discurso oral, de uso corrente, empregado em conversa", ou

TRADTERM, 15, 2009, p. 41-58 
seja, "coloquial". Diz-se: razgovórnyi iazzyk ("linguagem coloquial"), razgovórhyi stil' ("estilo coloquial") etc. E tal significado também entra na percepção, pelo leitor, do referido adjetivo na inusitada combinação com o substantivo jénchtchina ("mulher"); tem-se, então "casamenteira" = "mulher coloquial". Damos de barato o fato de que hoje se usa muito a palavra "colóquio" para designar eventos científicos, reuniões de especialistas para discussão de assuntos de uma área, mas esquece-se que significa "conferência entre duas ou mais pessoas; conversação" (Aulete, 1970:759). Como no parágrafo anterior, em que fomos ajudados pela homofonia entre o sufixo dador da ação frequentativa do verbo e o substantivo simbolizador do matrimônio, aqui a semelhança de sons vem de novo em nosso auxílio (o radical coloqu- é também o radical do verbo colocar no presente do conjuntivo). Aumentando em apenas mais uma sílaba o adjetivo, rebatizamos a diligente operária da base da nação por "mulher coloquianel", ou seja, mulher diuturnamente empenhada em conseguir que quem contratou os seus serviços coloque o anel de casamento na pessoa requestada. Em ambos os casos, houve um matrimônio de palavras, realizado ao custo de longo circunlóquio mas, esperamos, não muito ao arrepio das convenções e leis linguísticas:

- No nosso país, quando um homem quer mostrar uma intenção pra valer a propósito de uma moça, envia à frente uma mulher conversaliança (coloquialiança).

Os ingleses entenderam, mas responderam que mulheres coloquianéis para isso, eles não as tinham, e que isso nem era costume.

No exemplo, teve-se uma expressão (adjetivo + substantivo) arbitrariamente forjada, a que o contexto deu um significado. Em outra passagem Leskov faz o contrário: o contexto como que dissolve o significado de uma expressão corrente, ou seja, o adjetivo e o substantivo libertam-se do denominador comum (o significado, que formam juntos) e agem como números inteiros, cada um com a sua significação/valor original.

É o caso em que o canhoto, a navegar já para casa, teima em permanecer no convés, exposto ao vento e à chuva. Ele responde aos ingleses, que o convidam a recolher-se a um lugar abrigado,

TradTerm, 15, 2009, p. 41-58 
que ali fora para ele era melhor, pois poderia sentir-se mal. No original, aparece morskáia svinka (literalmente, "porquinha do mar"), que significa "porquinho da Índia, cobaia", mas o Autor quis dizer morskáia boliézn (literalmente, "doença do mar" - "enjoo"). Aproveitaram-se os dois significados da palavra svinka ("leitoa" e "parotidite"); parotidite, doença popularmente conhecida como "trasorelho", "orelhão", "caxumba", é a inflamação das parótides, glândulas salivares, situadas atrás das orelhas. A região do corpo afetada é a do pescoço; "pescoço" (mais especificamente, a sua parte posterior) tem, como sinônimo, a palavra "cachaço" que, por sua vez, vem a ser sinônimo de "porco"; data vênia aos médicos, reduzimos a parotidite ao pescoço por ela afetado (pescocite'! cachaçonite), porque, assim, primeiro, com cachaçonite conseguimos ter parotidite e porco na mesma palavra, como no original; em segundo, porque a palavra cachaçonite permite interpretar-se, também, como "comportamento igual ao de um cachaço" (quando uma pessoa, A, toma atitudes impróprias, indignas, iguais às de outra, $\mathrm{B}$, costuma dizer-se: A teve uma crise, um ataque, de B-ite, B-nite), e é essa interpretação que o Autor também contempla quando a personagem diz: so mnoi sdiélaettsa morskaia svinka (vai dar-me uma cachaçonite, e eu vou fazer sujeira, como um porco; e ela desengolirá o que tiver no estômago). Enfim, a expressão porquinha do mar deixa de significar um pequeno roedor malhado e anuro de terra firmíssima para indicar, literalmente, uma porquinha no mar, um homem que sujará o convés do navio como um porco.

As elocubrações do tradutor, por outro lado, não podem vitimar a personagem e atentar contra os bons créditos do autor. É altamente improvável que um morador lusófono da profunda província dissesse "cachaçonite"; isso, na sua boca, não soaria natural, apesar de ele, homem do interior, conhecer profundamente os maus hábitos dos membros menores da família dos Artiodáctilos. Para além disso, o mais de água que já viu foi o ribeirão da sua vila, e de água salgada, então, só meia panela, e isso para fazer comida. Assim, da mesma forma como o seu colega russo não usa a palavra correta (morskaia boliezn', "doença do mar") para designar o malestar provocado pelo balanço de um navio aos passageiros desacostumados a um piso oscilante, ele também não pode dizer "enjoo", como vemos na tradução estadunidense:

TRADTERM, 15, 2009, p. 41-58 
Nas traduções estadunidense e espanhola contornou-se a questão:

$$
\text { - No - respondía -, estoy major aquí fuera. Bajo techo, el }
$$

balanceo acabaría comigo. (106)

A troca do sufixo -ite, da área médica, indicador de irritação ou inflamação de algum órgão, por -ice, "que exprime a qualidade abstrata e ordinariamente com um sentido depreciativo ou burlesco" (Aulete, 1970), muito presente na linguagem falada ("doidice", "invencionice", "esquisitice" etc.), dá uma palavra mais coloquial, cachaçonice, mas, por outro lado, com o inconveniente de lembrar álcool (cachaça), no Brasil. Devolvamos à porquinha do original o seu nome de nascença e designemos o enjoo como uma parotidite com vômito, que é o seu principal sintoma:

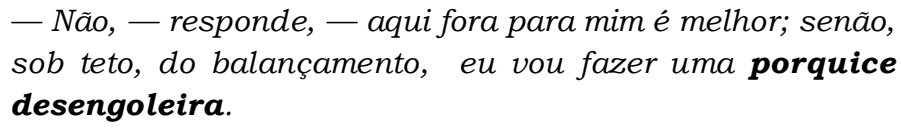

À luz do que foi dito, o procedimento mais característico de Leskov na sua prosa literária é a deturpação de palavras no espírito da etimologia popular, a combinação inusitada de palavras corriqueiras e a criação de termos misteriosos e enigmáticos para a caracterização ou descrição deste e daquele fato ou fenômeno; e tudo isso é feito para robustecer a palavra, libertar toda a expressividade nela existente em potência. Tal procedimento, obviamente, não se limita apenas ao estilo, no sentido de ser um gracejo ou chalaça para fazer o leitor rir. Ele é, também, um procedimento da intriga, um elemento fundamental da construção do enredo. As palavras, inventadas por Leskov de diversas maneiras, propõem ao leitor pequenos enigmas e adivinhações, que lhe excitam a curiosidade, nas fases intermediárias do desenvolvimento do enredo. Leskov comunica ao leitor essas invenções linguísticas, essas alcu-

nhas estranhas e essas definições misteriosas, antes de dar-lhe o

TRADTERM, 15, 2009, p. 41-58 
material necessário para a compreensão delas; com isso, dota a intriga principal de um interesse complementar.

Se o tradutor não tem isso em mente e não tem a coragem de enfrentar os editores inimigos das notas de rodapé, ele passa a ver no leitor o ingênuo consumidor de livros de autoajuda ou esotéricos, que aceita qualquer coisa, de preferência o vazio e destituído de sentido, quando quem se propõe a ler Leskov, tal como o leitor dos clássicos de todos os povos, é pessoa com sensibilidade e inteligência ávidas do fino trabalho de urdidura da renda de nervos, que é a linguagem da grande literatura.

O trabalho da tradutora espanhola é elogiável e aponta na direção certa: traduzir o texto original na íntegra, usar notas de rodapé nas passagens obscuras para o leitor estrangeiro e tentar reproduzir ao máximo as peculiaridades do estilo do autor.

Já o tradutor estadunidense caminhou no sentido oposto. Traduziu apenas o sentido das frases russas, não conservou nada do que caracteriza a linguagem de Leskov e, para além de desdenhar as notas explicativas, suprimiu sumariamente duas notas de rodapé do escritor russo (uma, inclusive, com seis linhas), em que este explicava aos seus compatriotas as características de uma bebida do Cáucaso e relatava um fato da biografia de uma pessoa citada no conto. Tal método de trabalho é um exemplo que não deve ser seguido.

\section{Referências bibliográficas}

AULETE, Caldas (1970) Dicionário contemporâneo da língua portuguesa em cinco volumes. São Paulo: Editora Delta, $5^{a}$ ed.

GÓRKI, M. (1952) O literatúrie (Acerca de literatura). Moscou: Editora Estatal de Belas Letras.

GROMOV, P. P. \& ÊIKHEMBAUM, B. M. (1956) N. S. Leskov. In: LESKOV, N. S. Sobránii sotichiniénii v odinnatsati tomakh (Obras Reunidas em onze tomos). Moscou: Editora Estatal de Belas Letras, tomo 1, pp. V-LX.

LESKOV, N. S. "Levchá" (O canhoto). Sobránii sotichiniénii v odínnatsati tomakh (Obras Reunidas em onze tomos). Moscou: Editora Estatal de Belas Letras, tomo 4, pp. 122-187.

TRadTerm, 15, 2009, p. 41-58 
LESKOV, Nikolai (2003) The enchanted wanderer. New York: Random House, Trad. David Magarschak.

(2007) La pulga de acero. Madrid: Editorial Impedimenta, Trad. Sara Gutiérrez.

TradTerm, 15, 2009, p. 41-58 